\title{
Quince días largos: la pandemia en una comunidad terapéutica para usuarios de drogas en Lambayeque (2020-2021)
}

\author{
Renzo Josue Caycay Carpio \\ Universidad Nacional Pedro Ruiz Gallo (Lambayeque, Perú) \\ renzocaycay@gmail.com \\ (iD) https://orcid.org/0000-0003-1213-3559
}

\begin{abstract}
Resumen
La falta de atención en salud mental en Lambayeque ha motivado la creación de proyectos informales de rehabilitación y sanción del uso de drogas en jóvenes. La presente investigación busca comprender cómo se ensambla el programa de una comunidad terapéutica con la lógica de la inmunidad médica durante la pandemia de la COVID-19. Esta última trajo consecuencias sobre la salud y economía de las familias, que reducen la capacidad financiera de los proyectos de rehabilitación. A partir de un trabajo etnográfico y de narraciones de cinco internos sobre sus primeros quince días de cuarentena en el establecimiento, mostramos que, lejos de representar una limitación organizativa, la pandemia consolida los procedimientos disciplinarios de este y otros complejos punitivos, clínicos y mentales. En comparación con la situación conocida, la nueva modalidad de recepción preventiva de la enfermedad resulta funcional al proceso de programación que convierte al individuo en un objeto susceptible de reformulación y transformación.
\end{abstract}

\section{Palabras clave}

Comunidades terapéuticas, usuarios de drogas, pandemia, disciplina, violencia informal 


\title{
Fifteen long days: the pandemic in a therapeutic community for drug users in Lambayeque
}

\author{
Renzo Josue Caycay Carpio \\ Universidad Nacional Pedro Ruiz Gallo (Lambayeque, Perú) \\ renzocaycay@gmail.com \\ (iD) https://orcid.org/0000-0003-1213-3559
}

\begin{abstract}
Resumen
The lack of mental health care in Lambayeque has motivated the creation of informal projects for the rehabilitation and punishment of drug use in young people. This research seeks to understand how the program of a therapeutic community is assembled with the logic of medical immunity during the COVID-19 pandemic. The latter had consequences on the health and economy of families, which reduce the financial capacity of rehabilitation projects. Based on an ethnographic work and the narratives of five inmates about their first fifteen days of quarantine in the establishment, we show that, far from representing an organizational limitation, the pandemic consolidates the disciplinary procedures of this and other punitive, clinical, and mental complexes. Compared with the known situation, the new modality of preventive reception of the disease is functional to the programming process that turns the individual into an object susceptible to reformulation and transformation.
\end{abstract}

\section{Palabras clave}

Therapeutic communities, drug users, pandemic, discipline, informal violence 


\section{Introducción}

Cinco centros especializados de salud mental no son suficientes para una población aproximada de 1 millón 300 mil habitantes en la región Lambayeque. El problema es similar si hablamos de reclusorios: el Centro Penitenciario de Picsi y el Centro de Diagnóstico y Rehabilitación Juvenil (CDRJ) de Chiclayo presentan graves cuadros de hacinamiento. Ante esta falta de alcance del Estado, surgen - por iniciativa ciudadanaproyectos privados, informales y comunitarios que se ocupan del tratamiento y el control de la desviación juvenil. Este proceso inicia, según la literatura (Zárate, Aragón y Morel, 2013; Chávez, 2009), en la década de 1990, por un lado, con la liberalización del Estado; y, por otro, con la agudización de la informalidad, la inseguridad ciudadana y violencia urbana. Lo anterior extiende sus efectos a las primeras décadas del siglo XXI para agravar la crisis de atención en salud mental durante la pandemia.

En la línea de otras investigaciones (Meini, 2020; Pérez et al., 2021; Jefferson, Caracciolo, Kørner y Nordberg, 2021), el presente texto es un intento de descifrar el estatus de la desigualdad de los dominados en pandemia -grupos que ven duplicada su condición de excepción y limitaciones-. Tenemos como protagonistas a usuarios de drogas internos en centros de rehabilitación, para quienes el confinamiento es una redundancia y la crisis que este acarrea agrava aun más su ya difícil internamiento. En concreto, se suspendieron las visitas, se cancelaron las terapias presenciales y se redujo la ración de alimentos. Algunas familias no pudieron cubrir el costo de su mensualidad; otras encontraron un motivo para abandonar a su familiar. Nos orienta la pregunta de qué implicancias tiene lo anterior en el ejercicio de poder que los objetiva.

Un gran porcentaje de nuestra narración se teje a partir de una etnografía prolongada en una comunidad terapéutica (CT, en adelante) del distrito de Lambayeque a razón de una investigación de más largo aliento. De repente, llegó la pandemia del coronavirus y trajo una emergencia que jugó en contra del trabajo de campo, pero que, a pesar de todo, no detuvo ni la reclusión de los residentes ni el interés académico por estudiarla. Fue, más bien, todo lo contrario. Tiempo después, regresamos al ambiente, donde la conversación con los nuevos miembros actualiza nuestra información empírica del fenómeno y nos hace pensar en la confluencia del gran encierro terapéutico y el gran encierro sanitario. En esta visita, un usuario de marihuana de 19 años que fue internado durante la pandemia nos habló sobre sus primeros quince días de cuarentena en la CT, detallados como especialmente difíciles. Esta conversación permitió afinar el planteamiento.

Nos interrogamos, entonces, qué sucede con la disciplina en una CT tras la aplicación de las medidas de aislamiento obligatorio entre 2020 y 2021. ¿Cómo incide la crisis sanitaria interna y externamente en la institución? y ¿cómo influye en la experiencia de los residentes? Como orientación, mostraremos el modo en que la cuarentena acentúa la capacidad disciplinaria de las comunidades terapéuticas, comparando los quince días iniciales de internamiento -etapa que responde a los rituales de programación de los nuevos residentes- antes y durante la pandemia.

Tras notar que no se trata de un caso aislado, nos preguntamos también en qué medida sirve para comprender la dinámica general de las CT. Esta crisis pone de 
relieve las comparaciones con complejos residenciales de personas ahora doblemente vulnerables. Asistimos, entonces, a la reflexión sobre la pandemia como una normalidad de la anormalidad (De Sousa Santos, 2020) y estado de excepción hecho regla (Agamben, 2020). Por otro lado, como lo sugiere tal planteamiento, abordamos el problema con herramientas conceptuales de tradición biopolítica, proyectando el caso de los residentes de Lambayeque.

El estudio de las comunidades terapéuticas adquiere la justificación social de comprender la atención informal de la salud mental en provincias. Aunque los problemas de capacidad precedan al inicio de la pandemia, este es un marco en que crecen las dificultades para los pacientes. Asimismo, su importancia académica reside en ofrecer una mirada sociológica de la construcción de identidades consideradas desviadas en un proyecto que se emparenta con formas oficiosas de administración de la violencia.

\section{Antecedentes}

El escenario interno de los usuarios de drogas en un complejo residencial ha sido abordado desde las ciencias de la salud, jurídicas y sociales. Revisaremos en breve sus principales aportes.

Como instituciones de salud mental, las CT son generalmente objeto de estudio de abordajes psicológicos. Según Güelman (2018), "históricamente han sido la psiquiatría y, en menor medida, la psicología, las disciplinas que han hegemonizado las investigaciones científicas que se emprendieron sobre la temática” (p. 165). Desde estas ciencias psicológicas peruanas, se han estudiado las estrategias de afrontamiento de la adicción (Rodríguez Chacón, 2012; Solano Melo, 2017) y los mecanismos psicosociales presentes en los residentes (Abramonte Vásquez, 2019; Caycho Caja, 2019). En menor medida, se ha abordado el efecto de la rehabilitación sobre los familiares y el personal (Moreno Usquiano, 2017; Chavarry Romero, 2019). Como veremos más adelante, la experiencia de residentes y familiares es crucial para conocer cómo se recibe la intervención. Además de la consistente cantidad de estudios, el abordaje psicológico resulta importante por ser constitutivo de la lógica de tratamiento en las CT. Este es el criterio científico que orienta los elementos del programa terapéutico contra el consumo de drogas, así como los conceptos con que los actores designan reflexivamente el internamiento.

Por otro lado, se ha estudiado las prácticas dentro de las CT con enfoque jurídico para denunciar los riesgos para el derecho a la salud de internos en España (Del Val, Frutos y Yagüe, 2014) o para los derechos humanos en el entorno peruano (Galli, 2012; Mollinedo Peralta, 2018). Como los estudios psicológicos, estos tienen de fondo una interpretación racional valorativa que confronta malas prácticas de determinados actores, lo que les permite proponer mejores orientaciones de organización. Dado que se examina el tratamiento en comunidades nacionales y locales, algunos de estos textos contienen trabajos de recolección de percepciones, historias de residentes y datos demográficos que fundamentan nuestro caso.

Otro grupo de estudios procura ofrecer la objetividad suficiente para entender la profundidad de un fenómeno desde la teoría social. La investigación de Lurbe Puerto 
(2006) emplea un enfoque sociológico que interpreta la formación de los internos como sujetos desviados en dos ciudades de Europa, en un fuerte nexo con la migración y marginalidad. En la misma línea, para el caso de Latinoamérica, Castrillón (2008) estudia la identidad y subjetividad en cinco CT de Colombia, y llega a una tipificación del tratamiento entre laico, cristiano y evangélico. Sobre las organizaciones religiosas contra las drogas en Argentina, Güelman $(2017,2018)$ esboza un sugerente análisis de la conversión y el encierro total como discurso de rehabilitación en dos CT. Por su parte, Di Leo (2019) examina su implicancia espiritual sobre el yo de los consumidores. Estos trabajos consideran a las CT como dispositivos de modelación de sujetos, de ahí que sea recurrente en este abordaje el uso teórico de la biopolítica de complejos punitivos y disciplinarios. Rescatamos, así, su modo de entender los mecanismos de poder y discursos tutelares.

Finalmente, la literatura que considera la pandemia nos ubica en el contexto de los riesgos sociales de la intervención en salud mental. Se ha dado cuenta del efecto de la pandemia sobre grupos ya en riesgo de violencias, maltratos, encierros, como las poblaciones penitenciarias en países del sur global (Jefferson et al., 2021; Meini, 2020). La psicología, por su parte, ha retomado los estudios de la relación entre adicción y tratamiento durante la emergencia sanitaria. Rojas (2020) entiende la cuarentena como un escenario de aumento del consumo de drogas por las condiciones psicológicas y sociales del encierro y el aislamiento. Asimismo, Villaverde, Fernández, San Narciso y Povedano (2020) revisan la influencia de la pandemia en el uso de drogas en Asturias y las estrategias de tratamiento sanitario obligatorio.

Hasta la fecha, no se ha publicado en el Perú un análisis de la dinámica social de los centros de rehabilitación de drogas en el escenario de la emergencia sanitaria. Esperamos que el presente coadyuve a cubrir esa falta. Por otro lado, considerando las limitaciones de los antecedentes, es necesario un abordaje íntimo que vaya más allá del discurso organizacional para entender las percepciones, códigos y conceptos de la residencia. Las investigaciones desde la teoría social nos enseñan que la disciplina de una institución total se cimienta en lo más profundo de la vida cotidiana, de ahí que sea menester una etnografía en la comunidad (Goffman, 2001 [1961]; Becker, 2016). Esta ha de ser complementada con técnicas de conversación. Como a Martín et al. (2020), nos interesa el testimonio de un residente para iniciar la comprensión de los demás.

\section{Método y materiales}

Si bien el mayor número de CT del departamento de Lambayeque se ubica en la zona periurbana de Chiclayo, trataremos con una comunidad del distrito de Lambayeque que, por su cercanía con el valle La Leche, recibe jóvenes de familias de franco proceso de cambio estructural, así como migrantes de la macrorregión norte ${ }^{1}$.

1 Lambayeque es un espacio de convergencia comercial y destino migratorio para ciudadanos de Cajamarca, Amazonas y San Martín. Tradicionalmente, su principal actividad económica es la agricultura de arroz y cańa de azúcar. Con el presente siglo, la instalación de importantes empresas de agroexportación en los valles del río La Leche modifica la estructura rural y social de la región (Aldana Rivera, 2006). 
Como se adelantó, antes de la pandemia, llevamos a cabo el trabajo de observación participante en la CT de manera intermitente entre agosto y noviembre de 2019, a efectos de un proyecto de investigación etnográfica. Las observaciones convivenciales de la organización, las rutinas y rituales de los actores fueron registradas en el ambiente mediante notas de campo, grabaciones y bitácoras de voz. Así también, en el campo, mantuvimos conversaciones grupales y personales con los principales actores (residentes, exresidentes, familiares, personal y directivos), lo cual sedimentó los significados del fenómeno. A continuación, se intenta una descripción fiel de los procesos disciplinarios de acuerdo con esta versión compartida colectivamente. Dado que se trata de un ambiente informal y consolidado, su relato está necesariamente teñido de códigos y jergas específicas que mezclan categorías terapéutico-religiosas y expresiones coloquiales urbanas.

Durante la pandemia, entre octubre de 2020 y febrero de 2021, realizamos tres visitas de cinco horas a la CT con el objetivo de llevar a cabo entrevistas semiestructuradas a los nuevos miembros. El establecimiento se caracteriza por el espacio abierto, rodeado de altos muros. Consiste en un amplio patio, donde se llevan a cabo todas las actividades (e.g. comidas, terapias, juegos, oraciones, ejercicios, etc.). Tienen techo únicamente los dos niveles de habitaciones, los baños no tienen puertas y las oficinas no cuentan con paredes.

En una primera jornada, se llevaron a cabo entrevistas a cinco interlocutores, uno de los cuales -de quien hablamos en la introducción-fue internado por primera vez durante la pandemia. Fabio ${ }^{2}$ es un adolescente de 19 años cuya madre lo internó en contra de su voluntad al enterarse de que consumía marihuana. Según nos narra, desde hace unos meses, "fumaba hierba" ocasionalmente con amigos del barrio, y no se considera delincuente o "maleante, como los que están acá". A diferencia de otros residentes -reincidentes o ingresantes más antiguos que él-, Fabio va a conocer las normas del centro cuando la institución se ha adaptado a las disposiciones estatales de aislamiento físico en pandemia. Las narraciones sobre su cuarentena de quince días sentado abrieron el interés de la presente investigación, y así se planificaron las dos siguientes visitas.

La investigación sobre las CT en pandemia tomaba forma con la desculturación en quince días, es decir, el efecto subjetivo de este nuevo recibimiento. Después de analizar la información, fue posible ordenar los códigos y categorías, diseñar una nueva guía, y entrevistar a otros cuatro residentes que pasaron la misma cuarentena. En la segunda y tercera visita (de pocas horas), conversamos con estos ingresantes, a quienes la quincena les resultaba novedosa y especialmente difícil, pese a que ya habían estado internados anteriormente. Este último supone un corpus de importancia para la valoración comparativa.

2 Se trata de un seudónimo. Mantendremos los nombres propios de personas e instituciones en silencio ético. 


\section{Normalidad}

\subsection{Centros de rehabilitación}

Presentaremos brevemente el ambiente social de los centros de rehabilitación de drogas para entrever su funcionamiento antes y durante la pandemia.

Centro de rehabilitación o casa hogar es como los actores (personal, residentes y familiares) denominan a la institución que ofrece un servicio residencial para personas con problemas de comportamiento, en su mayoría jóvenes usuarios y adictos a las drogas. Tiene la forma de una unidad grupal homogénea que descultura a sus miembros y los somete a una efectiva socialización según las diversas finalidades, cercana a la forma de las instituciones disciplinarias modernas (e.g. ejército, escuela, cárcel, partido político) y a las agrupaciones espirituales (e.g. grupos de ayuda, iglesias, sectas, cultos). En su momento, instituciones estatales y religiosas, desde mediados del siglo XX, por ejemplo, sometían tutelarmente al indio migrante (Nugent, 1992 [2012]), pero, en el presente siglo, aíslan a adolescentes y jóvenes de acuerdo con las nuevas condiciones: violencia urbana y drogadicción (Valenzuela, 2015). A partir de la década de 1980, ambos tipos de instituciones se ven extendidas por Latinoamérica en redes internacionales con una prédica conservadora. Los centros de rehabilitación en el Perú aparecen con gran intensidad a partir de la década de 1990. Coinciden con una nueva normativa constitucional y penal vigente sobre el uso de drogas y procesos que cambian la identificación del sujeto desviado, como la inseguridad ciudadana, la sociedad informal y la lucha estatal contra la producción y el consumo de drogas (Zárate, Aragón y Morel, 2013; Manrique et al., 2015).

A diferencia de las instituciones estatales y de algunas sectas espirituales, en el contexto descrito, el centro de rehabilitación asume una finalidad de lucro que origina lo que consideramos un proyecto empresarial. Esta comunidad ofrece un servicio de disciplina, reinserción social, terapia y salud mental ante la enorme brecha de atención en salud mental en las provincias del país. Como competencia del Ministerio de Salud (2018) y Devida (2021), el tratamiento estatal de las adicciones consta de estrategias comunitarias (e.g. charlas y talleres a cargo de municipalidades) y ambulatorias (e.g. centros especializados de salud mental), cuando no de instituciones residenciales. El Minsa coordina la prevención del uso de drogas con instituciones de la sociedad civil que sí ofrecen residencia, como Cedro y la Asociación de Comunidades Terapéuticas del Perú (ACTP), pero estas últimas se concentran en la capital ${ }^{3}$. En Lambayeque, se han implementado cinco Centros de Salud Mental Comunitarios en los distritos de Reque, Pátapo, Chiclayo, Illimo y José Leonardo Ortiz; por su parte, las comunidades terapéuticas resultan desatendidas, informales y clandestinas.

Definamos su naturaleza organizativa y su legitimidad. El centro de rehabilitación oficialmente toma la modalidad de comunidad terapéutica, definida como "el centro de tratamiento residencial para personas dependientes de sustancias psicoactivas y sus

3 El $78 \%$ de los miembros de esta asociación son CT de Lima. Ver https://actp.org.pe/ 
respectivas familias, [cuya] finalidad es la rehabilitación y la reinserción en la sociedad de la persona dependiente" (Ley 29765, 2011). El centro al que hacemos referencia es una empresa informal, sin registro en la ACTP, ni supervisión o administración del Minsa. Lo anterior es importante para apuntar que su consistencia interna no interactúa con la coacción física legítima, la administración de seguridad o justicia del Estado en la localidad, como lo haría una cárcel, un hospital psiquiátrico o un reclusorio juvenil. La disciplina y el arreglo de rutinas que forjan el proceso de rehabilitación nace, por el contrario, de la adopción empresarial de un programa terapéutico contra drogas, arreglo que recibe la legitimidad básica de las redes familiares o tutelares con las que se acuerda el servicio.

La reclusión puede tener diversos motivos bajo el común denominador de la presencia de un comportamiento transgresor a las normas sociales en sentido general, lo que incluye no solo la dependencia a sustancias psicoactivas (SPA), sino delitos, conductas antisociales, enfermedades mentales, demencia senil, intentos de suicidio, violencias, entre otros. Aunque los internos del centro de rehabilitación son, en su mayoría, usuarios de drogas -comúnmente Pasta Básica de Cocaína (PBC) y marihuana-. Los acompañan, asimismo, pacientes mentales, adultos mayores, alcohólicos y ludópatas ${ }^{4}$.

Con respecto a residencias como asilos o manicomios, un contraste de las CT es la falta de dictamen científico de la enfermedad o patología. Pocas veces un interno en estas comunidades es diagnosticado clínica o legalmente de forma previa a su tratamiento (UNODC, 2013). El manifiesto problema debió ser identificado por el entorno inmediato y familiar del interno, cuando no necesariamente por jueces, expertos o por ellos mismos. Güelman (2017) describe que, en las instituciones religiosas, el criterio es espiritual -falta de sentido de la vida-, lo cual es independiente de las diferencias entre consumo y consumo problemático, uso, abuso y adicción a la sustancia. La relación familiar -aludida en el concepto oficial de comunidad terapéutica- es indefectible en todos los casos, pues es el origen y el sostén (financiero) del tratamiento, a diferencia de otros establecimientos de reclusión. La familia o los apoderados sufren los efectos negativos que requiere y fundamenta la admisión de los internos en el centro. Estos solicitan el servicio de captura y reclusión, cierran el contrato de internamiento, pagan la mensualidad y mantienen los servicios de su apoderado.

Dejemos en claro, así, la importancia de las redes familiares de autoridad tutelar como pilar económico y fuente de legitimidad de un programa disciplinario informal y privado. Para el funcionamiento de la organización, son cruciales los recursos financieros y la cuota de confianza (externo), así como la consistencia discursiva del programa terapéutico y el orden jerárquico (interno). Veremos cómo incide la pandemia de la COVID-19 en ambos fundamentos de la institución.

4 De acuerdo con Galli (2012), “[las comunidades] están dedicadas, según sus propios creadores, exclusivamente a los adictos. [Sin embargo] más del $50 \%$ son personas con esquizofrenia, depresión, bipolaridad, orgánicos, seniles, adolescentes y niños con problemas de conducta". 


\subsection{Relaciones internas}

Puestos en contexto, revisemos ahora las relaciones sociales ordenadas en torno al programa, y los casos de los internos y el personal previo a la pandemia. El caso más recurrente es el de un varón joven o adolescente con problemas de adicción cuya madre trabajadora ha decidido tomar acciones para rehabilitarlo después de presenciar violencias, hurtos, pandillaje o asaltos, así como un deterioro en la personalidad y la imagen física y social de su hijo 5 . Con el fin de obtener la tranquilidad para el joven, para su familia y para sí misma, la madre se contacta con la administración del centro después del poco efecto de sus advertencias y la negativa de rehabilitarse voluntariamente de su hijo. En esta institución, la madre encuentra una oferta atractiva. Se le presenta una rehabilitación profesional, con métodos terapéuticos o espirituales, sin el empleo de la violencia y con vidas transformadas por la comunidad, un tratamiento - aunque costoso — preferible a los complejos penitenciarios para menores o adultos, y a los manicomios estatales, por suponer un servicio de reclusión que no requiere la mediación de una denuncia policial o un veredicto judicial's.

A diferencia de otras instituciones totales, el personal de los centros de rehabilitación se compone de exinternos, exadictos o adictos rehabilitados de la misma u otra comunidad. Abramonte (2019) menciona esta falta de personal no profesional como característica de las CT en el Perú. Castrillón (2008) encuentra, en Colombia, personal exadicto bajo el discurso del contacto permanente con el grupo como terapia antidrogas. Sobre la organización, según el artículo 4 de la referida ley de salud mental, las comunidades terapéuticas deben tener la estructura organizacional básica de dirección general, dirección administrativa, dirección médica y equipo terapéutico multidisciplinario. Esto se traduce, en los casos locales, en una dirección general constituida por el dueño/a de la empresa, una dirección administrativa compuesta por hermanos directores (exadictos), un equipo de especialistas contratados y -el grupo más extendidov un personal terapéutico de hermanos mayores.

Dejando en suspensión lo general, es preciso ahora presentar un ejemplo concreto con el objetivo de captar la aplicación de la jerarquía institucional en Lambayeque. La CT donde hicimos el estudio es una de las dos comunidades de un director general. En cada casa, funciona una dirección administrativa con personal contratado a sueldo, que consta de dos exinternos con amplia experiencia en el programa terapéutico. Estos hermanos directores establecen los acuerdos con las familias respecto de las mensualidades y nuevos ingresos. Asimismo, están a cargo del funcionamiento general de la comunidad, e intervienen en la administración de disciplina y las terapias. El equipo de especialistas consta, en este caso, de un psicólogo con un contrato de sesiones por horas a la semana, servicio que ofrece a más de una CT en la localidad, centros en los que también forma parte de la dirección médica. Además, la CT recibe esporádicamente la visita académica o

5 Este tipo de caso recurrente es descrito también por Chavarry (2019).

6 Chavarry (2019) presenta la narración de una madre que prefería comprarle en persona la droga a su hijo para evitar que lo interviniera la Policía. 
preprofesional de estudiantes de Psicología, Trabajo Social o Sociología de las universidades del departamento.

La situación del equipo terapéutico (hermanos mayores) remite un estatus híbrido entre la dirección y la residencia. Con este grupo comienzan y a la vez se difuminan las fronteras entre los hermanos directores y los adictos en rehabilitación. Desde ya, se aclara la diferencia respecto de una residencia mental formal: las comunidades terapéuticas desdibujan sistemáticamente la distancia social entre el personal y los internos que ve Goffman (2001 [1961]) en un hospital psiquiátrico, en el que "la movilidad social entre ambos sectores es sumamente restringida" (p. 21). Pese a que alguna vez ingresaron a la comunidad como internos, tienen el suficiente tiempo de residencia como para ejercer labores de disciplina hacia los menores. No dejan de ser adictos, pero fungen de personal de la empresa. Castrillón (2008) los entiende como "líderes u operadores terapéuticos, que coordinan actividades cotidianas del tratamiento, y contienen espacial y emocionalmente a los residentes" (p. 81). Al respecto, el psiquiatra peruano Enrique Galli (2012) denuncia lo siguiente:

Hacen las veces de terapeutas, en los más de los casos, algunos exadictos, a quienes se les paga una miseria; y los mismos pacientes se controlan unos a otros, se encargan de la limpieza, del arreglo del local y de funciones administrativas. (párr. 8)

Fuera del local, los hermanos mayores aseguran insumos necesarios para la familia ${ }^{7}$ solicitando periódicamente colaboraciones de comida en los mercados mayoristas de la ciudad. Según la opinión crítica de Galli (2012), "un buen porcentaje de estas casas explotan a los pacientes haciéndolos trabajar [sin paga] para fines lucrativos de los dueños". De este modo, siendo de gran utilidad para la empresa, establecen estrechos vínculos con la dirección general y la dirección administrativa -exadictos, como ellosque les permiten salir del claustro por su tiempo de limpieza, por la confianza conseguida o, finalmente, por el desarraigo respecto de su familia.

Damos cuenta de un mecanismo específico de privación de la libertad, cuyo criterio no obedece al pago de una deuda jurídica y moral con la sociedad -como el discurso penitenciario de la cárcel (Foucault, 2009 [1975]) - sino a la utilidad monetaria del internamiento. Sin ser hermanos mayores, los miembros cuyos padres no muestran interés alguno en su rehabilitación y que dejan, además, de pagar la mensualidad obtienen progresiva y tácitamente su libertad. Se les asigna trabajos dentro y fuera de la casa, dedicados a recuperar la inversión del centro en su estadía hasta que, dado el momento, el individuo decida no regresar de la calle.

Revisar lo que sucede con estos internos puede ayudar a terminar de comprender la posición crucial de las redes familiares en la institución. Veamos un caso singular. La prédica humanitaria y la imagen cristiana de la empresa -elemento de su legitimidadpermiten excepcionalmente la admisión voluntaria de adictos, personas que generalmente conocen el programa y reconocen que necesitan ayuda, un techo y comida. Aunque la forma contractual convencional se estreche con un apoderado, el trato para la reclusión del

7 De origen espiritual, familia es como se conoce a la totalidad de hermanos, lo que incluye residentes, operadores y directores de la comunidad. Utilizaremos cursivas para diferenciarla de la familia consanguínea. 
voluntario se basa en que demuestre su utilidad para la institución, ya sea en el cuerpo de operadores o en la búsqueda de alimentos. A pesar de este acuerdo, la dirección intentará -en los primeros días- ponerse en contacto con algún familiar del voluntario con el fin de establecer los términos contractuales de la rehabilitación y que se pague por su estadía. Un entrevistado voluntario previó el escenario y advirtió a sus familiares que no intervinieran: Yo fui una vez de voluntario, toqué la puerta y dije: "Necesito ayuda, quiero internarme". Me hicieron pasar a la oficina y me empezaron a preguntar. Ellos son drogos, todos son drogos y el drogo se malea, piensa siempre lo malo. Entonces me empezaron a preguntar dónde vivo, dónde trabajo, quién me ha mandado. Yo les dije [que] nadie. [...] Llamaron a mis hermanas. Yo les había dicho ya que si los llamaban del centro no paguen nada, ni un sol, porque si no, me cerraban la puerta. Cuando el director la llamó, rebotó; mi hermana le dijo que no tenía plata. (Entrevista, diciembre 2020; las cursivas son nuestras)

A partir de esta narración, advertimos una relación de ida y vuelta entre mensualidad y privación de la libertad, o, de forma más específica, entre una red financiera tutelar y el comienzo del programa terapéutico de rehabilitación. Sin embargo, el voluntario puede devenir, después de superar la incertidumbre e inestabilidad del primer mes, en último caso excepcional. Este es pagar su propio internamiento con un trabajo en la sociedad.

\subsection{Rituales de programación}

Expuestas las excepciones, se entenderán las reglas. Aunque hemos reseñado la residencia voluntaria, lo recurrente es la admisión de internos involuntarios, cuya familia cierra previamente el contrato con la dirección administrativa. Dicho contrato contiene el pago por la captura - una suerte de matrícula-, la primera mensualidad y una lista de insumos necesarios para la estadía, destinada a superar como mínimo los tres meses de desintoxicación según la recomendación psicológica. Pasaremos revista al modo en que se recibía a los residentes antes de la pandemia.

El traslado o captura consiste en la privación de la libertad de los individuos para su movilización al complejo de la CT. Constituye el primer ejercicio de violencia de la institución. Con ayuda de los familiares, dos o más operadores ubican al interno, ya sea en su vivienda o en la calle, e intentan persuadirlo para que no se resista al traslado, usualmente actuando "como una intervención de policías de civil" (Entrevista, febrero 2021), lo reducen y suben a un automóvil contratado ante la vista de eventuales acompañantes en el espacio público.

Estaba caminando en la esquina a la vuelta de mi casa, llegaron y se bajaron dos de una moto [mototaxi], me dijeron "ya súbete". Bueno fuera que hubieran dicho "somos del centro de rehabilitación" o "somos de la Policía". Me dijeron "ya súbete, tú has estado vendiendo droga, estás detenido por tráfico de drogas”. Era una zona con bastante gente y todos se quedaron a mirar, todos escucharon eso y me llevaron. (Entrevista, febrero 2021).

En la tesis de Mollinedo (2018), en una CT del distrito de Lambayeque, un interno señala de forma escrita: "Me trajeron involuntario, tipo rapto, por dinero" (p. 45). Una vez en la comunidad inicia el primer ritual, denominado short y polo en honor al modo en que visten al recién llegado para una ducha forzada. 
Te decían "Ya, short y polo". Yo no sabía qué significaba. Entré al baño y sacaron de una bolsa blanca un short y un polo. Me hicieron que me los ponga ahí frente a todos y me comenzaron a echar baldes de agua, con puñetes, de la nada. El agua duele más. (Entrevista, noviembre 2020)

Este ritual tiene como finalidad someter y despertar al individuo del shock de su secuestro. En lo subjetivo, es un despojo drástico de la seguridad corporal. Comienza con ambos procesos necesariamente acelerados, el rapto y la ducha, lo que Goffman (2001 [1961]) denomina profanación del yo del residente, el ataque a la integridad de su espacio privado y la intimidad de guarda sobre sí mismo: "Al someterse a todos esos manoseos el recién llegado permite que lo moldeen y que lo clasifiquen como un objeto que puede introducirse en la máquina administrativa del establecimiento" (p. 29).

Pese a que la poca literatura nacional y local lo sugiere (Galli, 2012; Mollinedo Peralta, 2018), este procedimiento no es indefectible en todos los casos. Lejos de una aplicación uniforme de las directivas, los operadores sopesan la reacción del recién llegado, su historial o procedencia para emplear más o menos fuerza de coerción. Es menos probable una bienvenida intensa contra internos de reacciones pacíficas que contra reincidentes o internos staff que oponen resistencia a que los chambeen. En este contexto, chambear tiene la acepción interna de aplicar la violencia física o psíquica como forma de quebrantar la voluntad y conseguir la obediencia. Se trata de trabajar u ocuparse totalmente de un residente ${ }^{8}$.

Tomando en cuenta a NIDA (2003, citado en Solano, 2017) el “Curso” correspondería a la primera de las tres etapas del modelo estándar de intervención en las CT: "La inducción y el tratamiento temprano ocurren durante los primeros treinta días, para adaptar a la persona a la filosofía de la CT. [Durante este tiempo], el nuevo residente aprende las políticas y los procedimientos básicos" (p. 67). Para Goffman (2001 [1961]), la disciplina y drasticidad del cambio de rutinas descultura al residente y lo sumerge en el proceso de programación. De este modo, se consigue su docilidad y utilidad. El planteamiento del NIDA (2015) es elocuente:

TCs use a highly regulated daily regimen with clearly stated expectations for behavior and psychological and behavioral rewards for working hard and meeting expectations. TCs also focus on empowering individuals by highlighting the strengths of program participants. Disciplinary sanctions for violations help to maintain structure for TC participants and staff and ensure that participants' lives are orderly and productive. (p. 4) ${ }^{9}$

De acuerdo con el programa de nuestro ejemplo, todo recién llegado pasa a formar parte del Curso, el puesto básico en la jerarquía en que se les asigna las tareas más duras y los últimos privilegios durante un mes, con el fin de constituir una experiencia consistente de aprendizaje -de ahí su nombre- de los valores, símbolos y las normas del centro. Por

8 Actividad estructurante de las instituciones totales y completas.

9 Las CT utilizan un régimen diario altamente regulado con expectativas de comportamiento claramente establecidas y recompensas psicológicas y de comportamiento por trabajar duro y cumplir con las expectativas. Las CT también se enfocan en empoderar a las personas destacando las fortalezas de los participantes del programa. Las sanciones disciplinarias por infracciones ayudan a mantener la estructura de los participantes y el personal de la CT, y garantizan que la vida de los participantes sea ordenada y productiva. (pág.4) 
otro lado, si la comunidad recibe un reincidente, vale decir, una persona que ya pasó por un Curso, este no lo vuelve a pasar obligatoriamente sino de manera excepcional como castigo. En una situación normal, el reincidente sería integrado prontamente a la labor en que se lo requiera. Como lo muestra el discurso científico del modelo de CT, el Curso constituye el filtro indefectible de socialización en el ambiente. Castrillón (2008) reconoce la función de este proceso en que el residente adquiere una identidad como sujeto denominado adicto en rehabilitación; así pues, se utiliza las actividades del mes de Curso para asegurar en el interno la conciencia de las normas que no asimiló y los privilegios que no valoró cuando libre para conjugar, de este modo, la exclusión moral, el tratamiento espiritual y la técnica política.

Me tenían loco cuando era Curso. Los días no pasaban. Tu mes de Curso era eterno. Me decían "Curso, haz esto; Curso, haz esto" y tienes que hacerlo dinámico [rápido] para que no te castiguen o no te pongan más días de Curso. (Entrevista, octubre 2019)

El director nos decía "Todo esto es para que valoren lo que tenían en la calle. Cuando tu mamá te servía tu buen desayuno en la mesa y tú lo dejabas por ir a fumar, de ahora en adelante lo vas a valorar”. Por dentro le estaba mentando la madre. (Entrevista, noviembre 2020).

Si bien el modelo terapéutico se refiere al tratamiento psicológico, las charlas, dinámicas, conversatorios y trabajos de grupo (National Institute of Drugs Abuse, 2015), lo que se entiende internamente como terapia comienza con el Curso mismo para designar elementos de corrección del comportamiento y las disposiciones. Tenemos en cuenta los sentidos específicos de la comunidad que, como se mencionó, intercambia habla especializada y coloquial. No es sorpresa el significado que adquiere lo terapéutico como algo en pésimas condiciones.

Un pan terapéutico es un pan duro; una taza de avena terapéutica es avena sin azúcar. (Entrevista, octubre 2019)

Es terapéutico algo que principalmente enseña, pero, además, trata, prepara y potencia; se convierte, entonces, en un modo de designar a los elementos de la objetivación. La disciplina del programa comienza con pie fuerte ese primer mes, pero se extiende durante todo el internamiento en la comunidad. Después del Curso, la noción de terapia está presente en el programa institucional en las sesiones cotidianas, así como en los castigos. De lo primero, Castrillón (2008) identifica algunos nombres de terapias grupales en CT de Colombia, tales como "encuentro de la mañana, la terapia de liberación de sentimientos, terapias de confrontación o de choque, terapias junto a las familias" (p. 83). Sobre lo segundo, por si no fue suficiente el Curso, tiene lugar la experiencia educativa. Con el objeto de continuar moldeando la identidad en rehabilitación, las experiencias educativas consisten en actividades con nombres descriptivos coloquiales, que pueden durar horas o días, y van desde simples órdenes hasta verdaderas torturas:

- Confrontación: gritar una orden en el oído

- Terapia de silencio: prohibido hablar

- Terapia de mono/rana/lagartija: hacer flexiones/ejercicios

- Terapia del amor: unir con esposas a dos residentes que se agredieron

- Terapia de chacha/sirvienta: oficiar de sirviente de la casa 
- Terapia de gula: comer en exceso

- Terapia de hombre noche: prohibido dormir

- Terapia del ahogado/terapia del té: ahogar al residente en un tanque de agua

\section{No normalidad}

El primer caso de COVID-19 se confirmó en el Perú el 9 de marzo de 2020. Seis días después, el Gobierno declaró el primer Estado de Emergencia Nacional (D.S. N. ${ }^{\circ} 044-$ 2020-PCM, 2020) y las primeras medidas preventivas contra la pandemia: inmovilización social obligatoria, suspensión de derechos constitucionales, recorte de libertad de tránsito de las personas, intervención de las FF. AA. y la PNP. Pensando en la cuarentena, cabría la premisa a priori de que esta población ya confinada está o tiene el potencial de estar mejor protegida respecto de otras frente a la pandemia. Por su vida cotidiana además de la estructura de su organización, la COVID-19 encontraría en mejores condiciones a centros residenciales, cárceles, correccionales, hospitales mentales, etc. Sin embargo, en la opinión de Meini (2020) sobre la situación de los penales, la pandemia "ha retirado los últimos vendajes que cubrían la crisis carcelaria, haciendo más evidente la vulneración de la salud de las personas privadas de libertad" (p. 570), lo que incluye constatar el hacinamiento y potenciales focos de expansión del virus en este tipo de instituciones.

Además de sustanciales riesgos sanitarios, peligran los recursos de la organización misma: ya no hay donaciones de insumos o comida, se reduce la capacidad financiera del proyecto empresarial, y, si ya algunas familias tenían deudas con la mensualidad, la crisis económica resultante las incrementó. Asimismo, la emergencia afectó a los internos. Por disposición estatal, los familiares detuvieron la visita y algunos, por ausencia, dejaron tácitamente la tutela a la organización. Si bien la declaración de emergencia motivó la decisión de retirar a algunos internos, en otros casos, la pandemia los alejó de sus esperanzas de salir del claustro. Mostraremos, además, el modo en que los residentes afrontan un problema específico: el endurecimiento de la disciplina.

\subsection{Quince días largos}

Una vez que abrieron la admisión de nuevos miembros, es posible comparar un internamiento antes y durante la pandemia. Dado que el proceso de captura no fue necesariamente modificado, el hecho resaltante es la forma en que las CT asumieron las medidas.

En la pandemia, los nuevos internos han de pasar quince días de aislamiento respecto del resto de la comunidad en rehabilitación, sin participar en sus actividades rutinarias y sin intercambiar palabra con los demás internos. Este es un obligado reposo para evitar posibles contagios de COVID-19 que pongan en peligro la vida de toda la gran familia del centro de rehabilitación. El nuevo miembro es sentado en una silla apartado del espacio, sometido a la vigilancia distante y constante de todos los miembros en general -que realizan sus actividades en el patio frente a él- $y$, en específico, de un interno guardia al que denominan informalmente su hermano sombra. Recibe tres comidas diarias en su silla, y no tiene permitido leer una revista o periódico -pues su reposo no debe ser 
interpretado con el tiempo de descanso o entretenimiento-, ni ponerse de pie más que para ir al baño. A la hora de dormir, en sincronía con los tiempos de la institución, el nuevo interno debe hacer su cama en el lugar de su asiento y descansar.

Nos tienen aquí sentados por la pandemia, no nos podemos parar. (Entrevista, febrero 2021)

Era horrible, aburrido. Veía que todos estaban haciendo algo y quería ir a ayudar, pero no podía moverme de mi silla. (Entrevista, febrero 2021)

Si bien el ritual de iniciación cambió y no se trata ya de un Curso intensivo de programación en el centro, este es un sufrimiento por omisión de movimiento que, a razón de prevenir el contagio por COVID-19, tiene peores experiencias y secuelas más eficientes en la disciplina del centro. Foucault (2009 [1975]) describiría esta ambientación de una zona de prevención dentro del establecimiento como un principio disciplinario que ofrece un "espacio recortado, inmóvil, petrificado, donde cada persona está pegada a su puesto" (p. 228), y donde, además, se despliega un riguroso sistema de registro y vigilancia permanente a cargo de un guardia. Nuestro entrevistado nos narra la transgresión de este muro construido como infranqueable de acuerdo con la coerción biopolítica:

A uno lo dejaron 20 días. Se salió de la zona a los catorce días. Se puso a hacer limpieza cuando le faltaba un día y le dijeron que se iba a quedar quince días más para asustarlo, pero solo le dieron cinco días más. (Entrevista, febrero 2021)

Bonastra (2006) estudia la institución política del lazareto, entendido desde el siglo XIV como un establecimiento sanitario de prevención contra una enfermedad contagiosa. En el caso de las CT, hablamos de un lazareto improvisado e individual y, por tanto, más compacto e incisivo. La silla de los quince días es el lugar de mayor intensidad de poder y control, que, sin importar las coordenadas físicas, se ubica en el extremo sur del sur. El sur, para De Sousa Santos (2020), "no designa un espacio geográfico, sino un espaciotiempo político, social y cultural" (p. 45); en los lazaretos de las CT, se ubica entonces el grupo que ve multiplicada sus formas de dominación, cumpliendo una "cuarentena dentro de otra" (p. 85).

Por su finalidad, la disciplina es un modo de ejercer el poder a través de la división del espacio y el control de los cuerpos. Definida por Foucault (2009 [1975]) como una relación de visibilidad sin lagunas, el interno sentado en la silla es un objeto identificable en todas sus expresiones. La disciplina es también un régimen temporal, cuestión que se resume en la forma en que nuestro primer interlocutor se refiere a tales quince días: días largos, en los que el tiempo corría pantanoso. Superados los quince días, el residente pasó a formar parte de las actividades de la comunidad como miembro del Curso, encargado de labores menores y específicas. Los primeros días en que dejó el descanso preventivo supusieron un confortante alivio. Ser Curso implicaba (por fin) su libre desplazamiento en el espacio, interacción con los demás internos, jóvenes como él, aunque desconocidos y dóciles. La diferencia con los días se torna drástica:

Cuando estaba en la silla quería hacer algo, ya cuando salí a Curso estaba más tranquilo porque podía caminar, hacer ejercicio. Pero después me llenaron de tareas y todo lo haces en el sol. Me ardían los ojos porque pasaba todo el día en el patio hasta las 6 p.m. A esa hora te dejaban tranquilo hasta la hora de dormir. (Entrevista, octubre 2020) 
Como se ha mencionado, el estado de emergencia modificó la frecuencia de visita de los familiares. Aunque puede conservar objetos de soporte de su antigua identidad (e.g. prendas, artículos de dormitorio, libros, juguetes), la falta de las visitas familiares es la pérdida del bálsamo que los mantiene conectados con el Yo, constantemente mutilado ${ }^{10}$.

Tras los casos reseńados, podemos reconstruir el concepto de comunidad terapéutica. Aparte de su definición legal, hemos asistido a la definición de Castrillón (2008, p. 80), como instituciones totales en torno a sistemas tutelares de cura social para usuarios de drogas. En la presentación de la organización, describimos estos mecanismos y redes tutelares. Ahora comprendemos qué tanto de institución total conserva en la pandemia. Goffman (2001 [1961], p. 18), quien acuña el concepto, señala como totales a las instituciones con tendencias absorbentes y totalizadoras. Estas tienen por característica elemental romper el ordenamiento (temporal y espacial) de antiguas actividades básicas para establecer una rutina férrea, con nuevas tareas estrictamente programadas en compañía de otros homogéneos en tiempos y lugares sincrónicos. $\mathrm{Al}$ ingresar a la institución, el interno ve atacada su cultura de presentación y desatendidas sus respuestas socializadas, situación crítica que, para Giddens (1995), genera el quiebre de la seguridad básica, desmonta la espacialidad del cuerpo y su interacción de la serialidad de las rutinas. El concepto se acerca a otros intentos por comprender los mecanismos disciplinarios. Con Goffman, se puede hacer referencia, por ejemplo, al individuo inserto en un sistema totalitarista arendtiano, recortes a la individualidad, actividades monótonas, sin sorpresas y absolutamente públicas. Una burocracia invisible que, sin embargo, para Foucault (2009 [1975]) tiene la función de explotar la visibilidad de los residentes en forma completa y austera.

\section{Para concluir}

Tras conocer las redes tutelares que sostienen las CT, nos preguntamos cómo incide la pandemia interna y externamente en la organización. La admisión de nuevos miembros nos permite constatar que, si bien atraviesan una crisis económica externa, las CT subrayan sus mecanismos disciplinarios al incorporar la cuarentena a su programa terapéutico. Esta apropiación del confinamiento viró nuestra atención de treinta días, duración del Curso o de la primera fase oficial del programa en las CT, a quince días largos de vigilancia permanente. No aludimos a un ahorro del tiempo de programación, sino a un tramo compacto biopolítico que se yuxtapone al modo convencional de desculturar y mutilar el Yo.

De acuerdo con la intención transversal del texto, la pandemia ha sido un instrumento de comprensión de la dominación de los internos. El material expuesto nos permite pensar en el modo en que los espacios autoritarios, instituciones totales y completas, de hecho, resultan efectivos para aplacar la crisis sanitaria pese y sobre la base del sometimiento de los residentes. Estos proyectos reemplazan y/o complementan informalmente las funciones de gobierno en la administración de la violencia, espacio, seguridad y justicia.

10 Di Leo (2019, p. 12), repasa, por su parte, que la pérdida de soporte familiar de residentes en una CT católica provoca una narrativa de crisis individual. 
En el estudio de las CT, valoramos la profundidad del abordaje etnográfico para entender las rutinas y significados colectivos de los residentes. Sin embargo, reconocemos como pendiente interpretar la residencia de las jóvenes usuarias de drogas en los mismos complejos en que se les añade otra condición de desigualdad. Así también es necesario prestar atención a las redes tutelares de las familias mediante el análisis del sentido que le otorgan a la institución o al proceso de rehabilitación. Pese a que tratamos con una comunidad ubicada espacialmente en el extremo comercial de un valle agrícola, una visión encerrada en la residencia peligra de desatender dinámicas estructurales, como los procesos de cambio social y modernización. En este sentido, queda por incluir las procedencias sociales de estos usuarios de drogas, el lugar desde el cual se interpreta su desviación y el modo en que convergen en una institución disciplinaria.

\section{Referencias bibliográficas}

Abramonte Vásquez, K. (2019). Motivación al cambio y riesgo de recaida en pacientes drogodependientes en cinco comunidades terapéuticas de Lima Sur [Tesis de grado]. Universidad Autónoma del Perú.

Agamben, G. (2020). ¿Enquépuntoestamos?Laepidemiacomopolítica.ArtilleríaInmanente. Obtenido de https://artilleriainmanente.noblogs.org/files/2020/06/2020-Giorgio-Agamben-En-qu\%C3\%A9-punto-estamos-La-epidemia-como-pol\%C3\%ADtica-Final-4.pdf

Aldana Rivera, S. (2006). Lambayeque y el norte peruano en un contexto mundializado. Investigaciones Sociales, (17), 311-334.

Becker, H. (2016). Cómo fumar marihuana y tener un buen viaje: Una mirada sociológica. Buenos Aires: Siglo XXI Editores.

Bonastra, J. (2006). Ciencia, sociedad y planificación territorial en la institución del lazareto [Tesis doctoral]. Universitat de Barcelona. Obtenido de http://diposit.ub.edu/dspace/bitstream/2445/42003/3/03.JBT_BLOQUE_II.pdf

Castrillón, M. D. (2008). Entre teoterapias y laicoterapias. Comunidades terapéuticas en Colombia y modelos de sujetos sociales. Psicología \& Sociedade, 20(1), 80-90. Obtenido de https://www.redalyc.org/pdf/3093/309326454009.pdf

Caycho Caja, A. (2019). Anomia social y personalidad en pacientes dependientes a drogas en comunidades terapéuticas de Lima [Tesis de maestría]. Universidad Nacional Mayor de San Marcos.

Chavarry Romero, S. (2019). Codependencia en familiares de usuarios de una comunidad terapéutica de Lima Este [Tesis de grado]. Universidad Autónoma del Perú.

D.S. N.o 044-2020-PCM. (15 de marzo de 2020). Decreto Supremo que declara Estado de Emergencia Nacional por las graves circunstancias que afectan la vida de la Nación a consecuencia del brote del COVID-19. Lima: Diario Oficial El Peruano. Obtenido de https://busquedas.elperuano.pe/normaslegales/decreto-supremo-que-declara-estado-de-emergencia-nacional-po-decreto-supremo-n-044-2020-pcm-1864948-2/

Del Val, C., Frutos, L., \& Yagüe, C. (2014). Derecho a la salud y prisión. Crisis y cambio. Propuestas desde la sociología: XI Congreso Español de Sociología, (1), 1218-1228. Obtenido de https://dialnet.unirioja.es/servlet/articulo?codigo=7279995 
Devida. (2021). Politica nacional contra las drogas al 2030. Comisión Nacional para el Desarrollo y Vida sin Drogas - Devida.

Di Leo, P. F. (2019). Construcción narrativa del yo y agencia en personas en tratamiento por consumo de drogas en organizaciones religiosas y espirituales. Aposta: Revista de Ciencias Sociales, (80), 8-26. Obtenido de https://dialnet.unirioja.es/servlet/articulo? codigo $=6984568$

Foucault, M. (2009 [1975]). Vigilar y castigar. Nacimiento de la prisión. Buenos Aires: Siglo XXI Editores.

Galli, E. (2012). ¿Centros de rehabilitación o centros de usura, maltrato y muerte? Revista Ideele, (220). Obtenido de https://revistaideele.com/ideele/content $/ \% \mathrm{C} 2 \% \mathrm{BF} c e n-$ tros-de-rehabilitaci\%C $3 \% \mathrm{~B} 3 \mathrm{n}$-o-centros-de-usura-maltrato-y-muerte

Giddens, A. (1995). La constitución de la sociedad. Bases para la teoría de la estructuración. Buenos Aires: Amorrortu.

Goffman, E. (2001 [1961]). Internados. Ensayos sobre la situación social de los enfermos mentales. Buenos Aires, Argentina: Amorrortu editores.

Güelman, M. (2017). Desconexión total. El aislamiento en los tratamientos en comunidades terapéuticas. En A. Camarotti, D. Leo, Pablo y D. Jones (Eds.), Entre dos mundos: abordajes religiosos y espirituales del consumo de drogas (pp. 137-164). Teseo.

Güelman, M. (2018). La rehabilitación del consumo de drogas como conversión. Un análisis de los programas de tratamiento de dos comunidades terapéuticas religiosas de redes internacionales. Cuadernos de la Facultad de Humanidades y Ciencias Sociales - Universidad Nacional de Jujuy, (54), 163-177.

Jefferson, A., Caracciolo, G., Kørner, J., \& Nordberg, N. (2021). Amplified vulnerabilities and reconfigured relations: Covid-19, torture prevention and human rights in the Global South. State Crime Journal, 10(1), 147-169. Obtenido de https://www. jstor.org/stable/10.13169/statecrime.10.1.0147

Ley 29765. (23 de julio de 2011). Ley que regula el establecimiento y el ejercicio de los centros de atención para dependientes, que opera bajo la modalidad de comunidades terapéuticas.

Lurbe Puerto, K. (2006). La enajenación de l@s otr@s. Estudio sociológico sobre el tratamiento de la alteridad en la atención de salud mental en Barcelona y París. [Tesis doctoral]. Universitat Autònoma de Barcelona. Obtenido de https://www.tdx.cat/ handle/10803/5125\#page $=1$

Manrique, H., Pastor, A., Mendoza, B., Sierra, J., \& Villegas, R. (2015). Política de drogas: debates contemporáneos y situación actual en el Perú. La Colmena, (8), 77-89.

Martín, N., Martínez, N., Usabiaga, O., y Martos, D. (2020). Los significados que una madre presa y drogodependiente asigna a las actividades físico-deportivas: sus relaciones con la reinserción y la terapia. RICYDE. Revista Internacional de Ciencias del Deporte, XVI(62), 381-395.

Meini, I. (2020). Privados de libertad, derecho penal y pandemia. En VV.AA., Derecho de los desastres: Covid-19 (pp. 551-567). Lima: PUCP.

Minsa. (2018). Lineamiento de política sectorial de salud mental Perú 2018. 
Mollinedo Peralta, P. (2018). La vulneración de los derechos fundamentales de los internos en las comunidades terapéuticas contra adicciones en la Región Lambayeque [Tesis de licenciatura]. Universidad César Vallejo.

Moreno Usquiano, Y. (2017). Clima social familiar en internos con consumo de drogas psicoactivas en la comunidad terapéutica Novo World de Carabayllo [Trabajo de Suficiencia Profesional]. Universidad Inca Garcilaso de la Vega.

National Institute of Drugs Abuse. (2015). Therapeutic Communities. NIDA Research Report Series.

Nugent, G. (1992 [2012]). El laberinto de la choledad. Páginas para entender la desigualdad (2da ed.). Lima: Universidad Peruana de Ciencias Aplicadas.

Pérez, L., Lavado, T., Velazco, J., Velazo, J., Vásquez, G., Osorio, S., \& Alayza, A. (2021). Tiempos de cuidados. Desigualdades, teoría feminista y trabajo de cuidado en el Perú. Aportes para transformar un sistema en crisis (Primera ed.). Lima: Oxfam. Obtenido de https://oi-files-cng-prod.s3.amazonaws.com/peru.oxfam.org/s3fs-public/file_ attachments/Tiempos-de-Cuidados-Peru.pdf

Rodríguez Chacón, A. (2012). Afrontamiento y soporte social en un grupo de adictos de un hospital psiquiátrico de Lima [Tesis de grado]. Pontificia Universidad Católica del Perú.

Rojas Jara, C. (2020). Cuarentena, aislamiento forzado y uso de drogas. Cuadernos de Neuropsicología. Panamerican Journal of Nuropsychology, 14(1), 24-28.

De Sousa Santos, B. (2020). La cruel pedagogía del virus. CLACSO.

Solano Melo, C. A. (2017). Estilos de afrontamiento y riesgo de recaida en adictos residentes en comunidades terapéuticas de Lima [Tesis de maestría]. Universidad Nacional Mayor de San Marcos.

UNODC. (2013). Tratamiento de la dependencia a PBC. En Pasta Básica de Cocaina. Cuatro décadas de historia, actualidady desafios (pp. 143-159). Lima: Devida.

Valenzuela, J. M. (2015). Juvenicidio: Ayotzinapa y las vidas precarias de América Latina y España. Barcelona: Ned Ediciones.

Villaverde, A., Fernández, M., San Narciso, G., \& Povedano, E. (2020). Adicciones durante el confinamiento por el Covid-19 en Asturias. Psicosomática y Psiquiatría, (15), 21-28.

Zárate, P., Aragón, J., \& Morel, J. (2013). Inseguridad, Estado y desigualdad en el Perú y en América Latina: un estado de la cuestión. Lima: Instituto de Estudios Peruanos. 